\title{
The effect of right versus left lateral-tilt position on compression of the inferior vena cava in parturients
}

\author{
Nobuko Fujita, M.D. ${ }^{1}$, Hideyuki Higuchi, M.D. ${ }^{2}$, Kan Zhang, M.D ${ }^{3}$, Shunichi Takagi, M.D. ${ }^{2}$, Shiori Sakuma, M.D. ${ }^{2}$, \\ Makoto Ozaki, M.D. ${ }^{2}$
}

1. Department of Anesthesiology, St. luke's International Hospital, Tokyo, Japan

2. Department of Anesthesiology, Tokyo Women's Medical University, Tokyo, Japan

3. Outcomes Research, Anesthesiology Institute, Cleveland Clinic, Ohio, USA

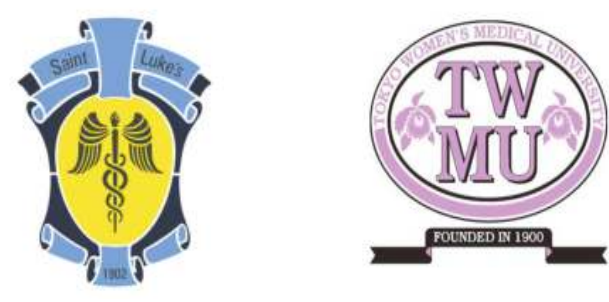

\section{Introduction}

A $15^{\circ}$ left-lateral tilt position has become an established practice of obstetric anesthesia since the 1970s, especially after the study by Crawford et al. ${ }^{1}$ who reported the significant improvement in the fetal clinical and acid-base status by tilting the patient with a wedge cushion at cesarean section. However, in their study the majority of the patients were tilted to the right since surgical access to the uterus was simplifies despite it was assumed to be anatomically disadvantage for IVC compression.

We recently reported that of a $30^{\circ}$ left-lateral tilt, but not a $15^{\circ}$ tilt, partially relieves compression of the inferior vena cava (IVC) in parturients at term without anesthesia. ${ }^{2}$ The effect of right lateral-tilt position on the IVC compression, however, in unknown. Here, we used magnetic resonance (MR) imaging to examine the effect of the right lateraltilt position on the IVC compression.

\section{Patients and methods}

\section{MR images of 10 singleton parturients (37 weeks} gestation) were obtained for observation of the IVC and aorta in both the supine, left lateral-tilt positions $\left(15^{\circ}, 30^{\circ}\right)$ and right lateral-tilt positions $\left(15^{\circ}, 30^{\circ}\right)$ with head to toe placement of a $1.8-\mathrm{m}$ long hard Vblock constructed of closed-cell polyethylene foam under the right side of the parturient's body (Fig.1).

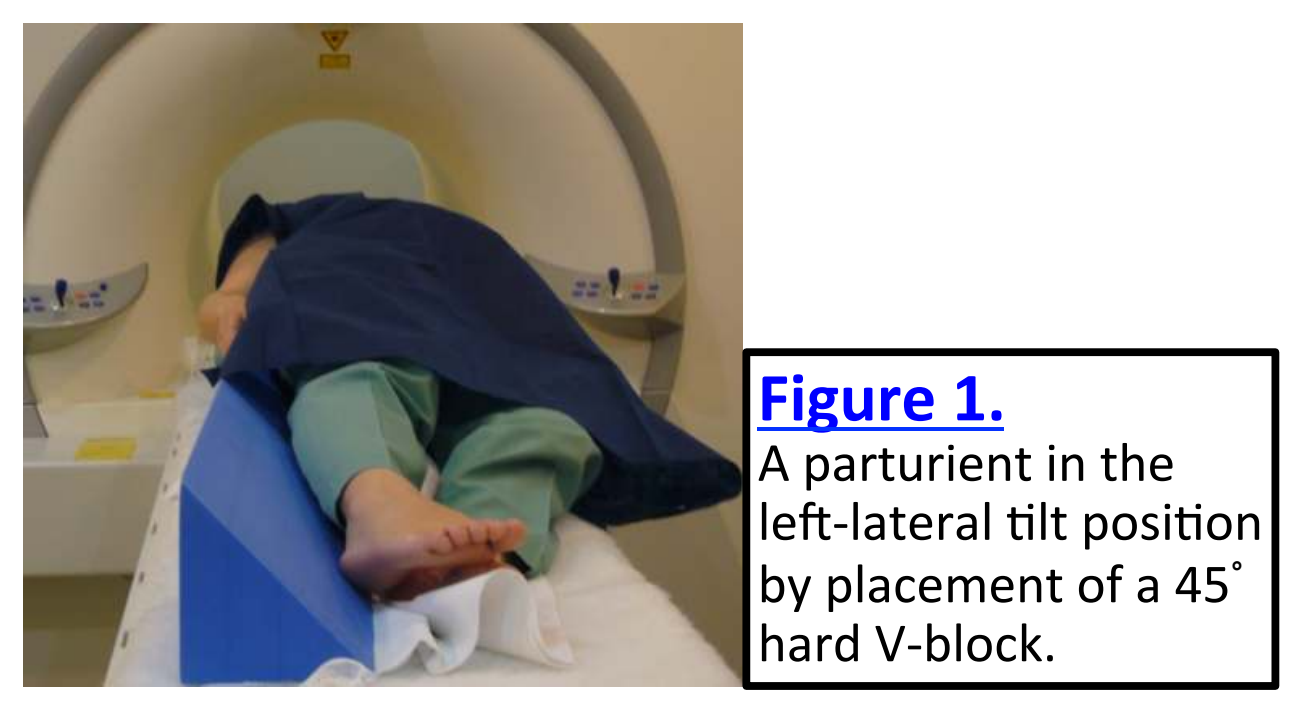

\section{Results}

In parturients, the abdominal aorta could be identified in any positions. Aortic volume did not change in any of positions. (Figs.2,3).

MR images revealed total compression of the IVC when parturients were in the supine positions (Figs. 2,3).

The IVC volume in the left lateral-tilt position was not increased at $15^{\circ}(7 \pm 5$ vs. $5 \pm 4 \mathrm{ml}$ ), whereas the corresponding values at $30^{\circ}$ were significantly increased $(11 \pm 8 \mathrm{ml})$, compared with the supine position $(P<0.05)$.

In contrast, the IVC volume in the right lateral-tilt position was increased not at $15^{\circ}(6 \pm 6 \mathrm{ml} ; \mathrm{P}=$ $0.24)$ or at $30^{\circ}(6 \pm 6 \mathrm{ml} ; \mathrm{P}=0.08)$ (Fig.4).
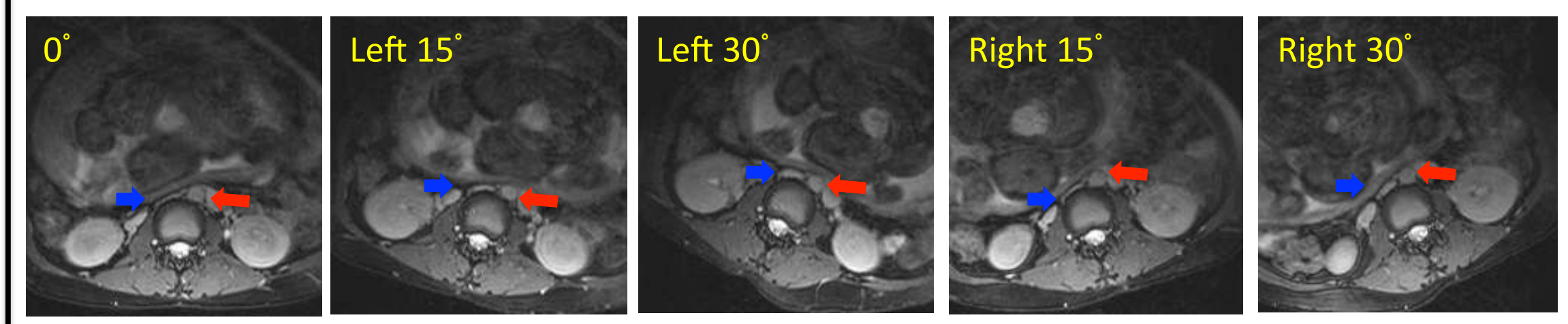

Figure 2. MR images of a 41-year-old pregnant woman (39 weeks) in the supine, left lateral-tilt positions $\left(15^{\circ}, 30^{\circ}\right)$ and right lateral-tilt positions $\left(15^{\circ}, 30^{\circ}\right)$ at the L3/4 disk level. The IVC $(\rightarrow)$ was almost completely compressed in the supine positions. At the $15^{\circ} \mathrm{left}$ and right lateral-tilt positions, compression of the IVC was slightly reduced. Compression of the IVC was reduced more in the $30^{\circ}$ left and right lateral-tilt positions than in the 15 left and right lateral-tilt positions. The size of the aorta $(\longleftarrow)$ did not significantly change in any position.
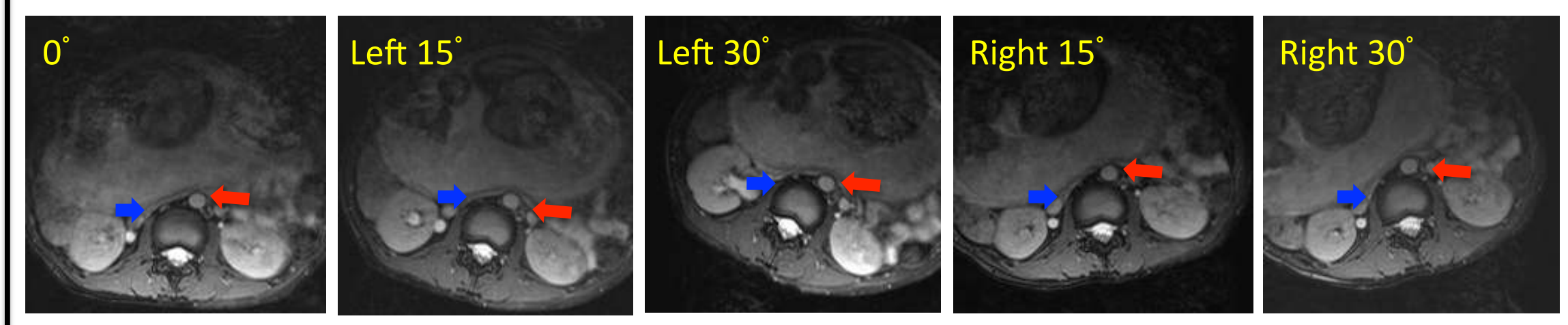

Figure 3. MR images of a 38-year-old pregnant woman (39 Weeks) in the supine, left lateraltilt positions $\left(15^{\circ}, 30^{\circ}\right)$ and right lateral-tilt positions $\left(15^{\circ}, 30^{\circ}\right)$ at the $L 2 / 3$ disk level. The IVC $(\rightarrow)$ was compressed in the supine position. In the left lateral-tilt positions $\left(15^{\circ}, 30^{\circ}\right)$ and right lateral-tilt positions $\left(15^{\circ}, 30^{\circ}\right)$, compression of the IVC was not reduced. The size of the aorta $(\leftarrow)$ did not significantly change in any position.

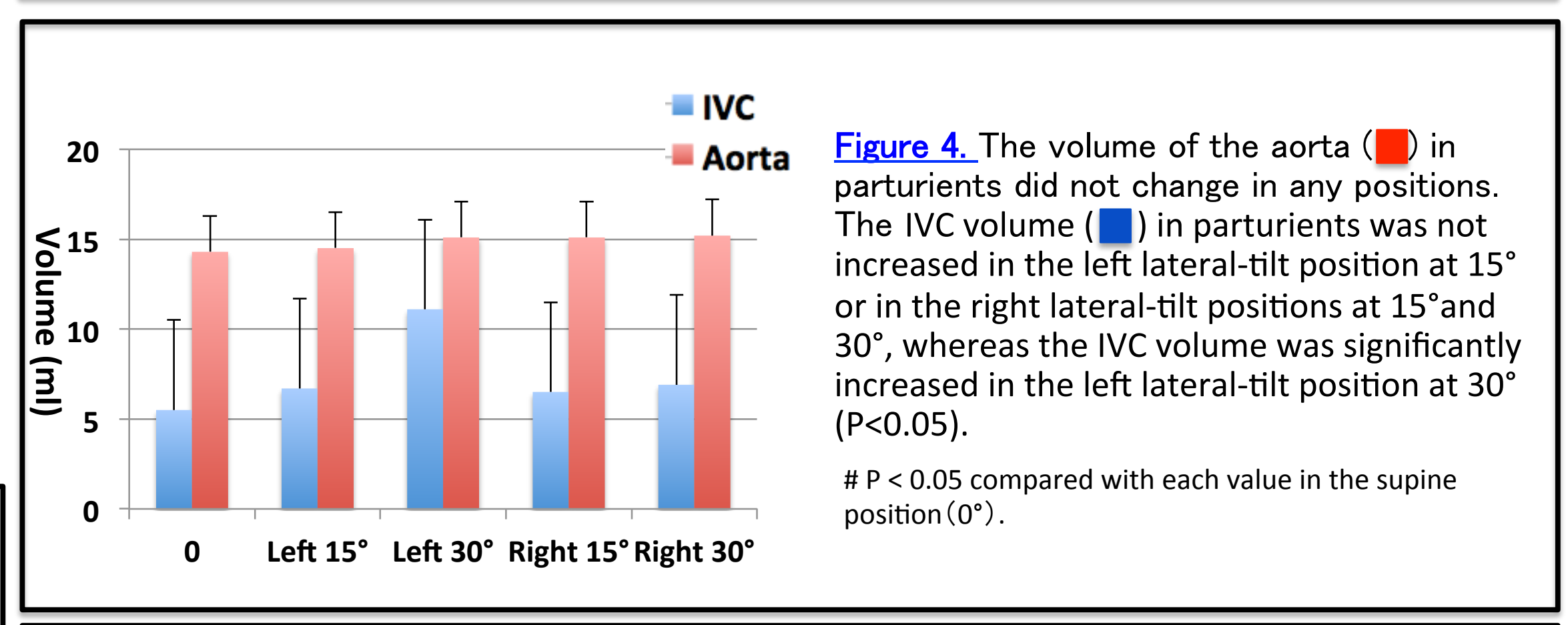

\section{Discussion}

- The present study indicates that the left and right lateral-tilt position at $15^{\circ}$ did not reduce compression of the IVC, consistent with our previous report. ${ }^{2}$

- These findings also indicate that the left lateral-tilt position at $30^{\circ}$, but not right lateral-tilt position at $30^{\circ}$, was effectively reducing compression of the IVC.

- Limitations

- Unanesthetized (no muscle relaxation, no block of sympathetic nervous system, no intravenous fluid)

- Healthy parturients

- Low resolution of MRI

- Small number of patients

\section{Conclusion}

- In parturients, the abdominal aorta is not compressed by pregnant uterus in any position.

- Only left lateral-tilt position at $30^{\circ}$ effectively reduces compression of the IVC. 